\title{
DEVELOPMENT OF HIP CONSOLIDATED P/M SUPERALLOYS FOR CONVENTIONAL FORGING TO GAS TURBINE ENGINE COMPONENTS
}

\author{
Gernant E. Maurer, Wayne Castledine, \\ Frederick A. Schweizer, and Sam Mancuso \\ Special Metals Corporation \\ New Hartford, NY 13413
}

\section{Abstract}

Recent investigations have identified thermal-mechanical processing conditions which significantly enhance the hot workability of P/M nickel-based superalloys. The process incorporates hot isostatic pressing (HIP) of powder at temperatures just below the solidus of the alloy. The hot ductility produced by this sub-solidus HIP (SS-HIP), has been found to be superior to that of powder metallurgy (P/M) superalloys that were either conventionally HIPed or extrusionconsolidated. The benefits of this new process have the potential of reducing processing costs and producing components with superior microstructures and properties.

The purpose of this study was to understand the mechanisms which are responsible for the excellent hot workability observed. A series of test samples was prepared from UDIMET* Alloy 720 material that was prepared using cast/wrought, P/M as-HIP, $\mathrm{P} / \mathrm{M}$ as-extruded and $\mathrm{PM} \mathrm{SS}-\mathrm{HIP}$ processing. High-strain rate tensile tests were used in an attempt to quantify the differences in forgeability. Microstructures were examined to gain insight into the mechanisms envolved.

This study provides convincing evidence that SS-HIP P/M processing can produce billets of highly alloyed superalloys, such as UDIMET*Alloy 720 and Rene' 95 , that can be subsequently thermomechanically processed by conventional open die forging or ring rolling. SS-HIIP P/M offers the unique combination of cast wrought workability and PM homogeneity including freedom from cast/wrought defects such as freckles and white spots. Due to this unique combination of properties, SS-HIP P/M parts costs should compare favorably to cast/wrought while offering the advantage of ultrasonic inspectability similar to PM parts. An additional benefit is the potential for super-solvus heat treatment grain size control not nossible in cast/wrought or conventional $\mathrm{P} / \mathrm{M}$ products.

* UDIMET is a registered trademark of Special Metals Corporation

\section{$\underline{\text { Introduction }}$}

Historically, P/M superalloy billets have not been amenable to high-strain rate deformation and, therefore, required $\mathrm{P} / \mathrm{M}$ billets to be isothermally forged under superplastic strain rate conditions. The ability to use conventional forging methods to make $\mathrm{P} / \mathrm{M}$ billets will result in lower conversion costs for production of the billet and the subsequent closed-die forged or ring-rolled components. In order to be able to conventionally forge a P/M superalloy, a process had to be identified that minimized the effects of prior particle boundaries Superalloys 1996
(PPB's) that are known to have a strong influence on their mechanical properties. .

The effect of PPB's in P/M superalloys has been extensively reviewed by Thamburaj and colleagues ${ }^{(1)}$. His conclusions are that PPB's are caused by carbon segregation and particle contamination. Both result in precipitation of PPB's, either as carbides, oxides, oxy-carbides, or possibly as oxy-carbonitrides. The volume of PPB's is dependent on many things including the atomization method, particle size, pre-consolidation handling and consolidation parameters. The cooling rate after consolidation and post consolidation heat treatments were also noted as factors affecting PPB's.

Much work has been done to understand and eliminate the effect of (PPB's) in PM products. The determental effects of PPB's on mechanical properties is well documented ${ }^{(1)(2)}$. It is generally agreed that as-atomized powder surfaces contain carbides, borides, nitrides, and oxides. It is theorized that these precipitates may prevent optimum diffusion bonding during solid state consolidation and that the oxides are sites for carbide and boride nucleation and growth during heat treatments ${ }^{(1)}$. Whether the cause is a boundary heavily decorated with precipitates or remnants of oxide films, studies have shown that PPB's are a weak link in the microstructure ${ }^{(2)}$.

Throughout the development of $\mathrm{P} / \mathrm{M}$ superalloys many alloy and process development efforts found ways to reduce the effects of PPB's. Alloy designers have attempted to reduce the powder particle surface decoration by reducing carbon and nitrogen and using higher HIP temperatures. The benefits of putting PPB's into solution were offset by the grain growth that occurred. Hack et $\mathrm{al}^{(3)}$ investigated HIP consolidation of a low carbon Astroloy alloy at temperatures above and below the boride solvus $\left(1220^{\circ} \mathrm{C}\right)$ of the alloy. The investigators identified the disadvantages of the higher HIP temperatures to be many. In addition to the difficulty in controlling the precise HIP temperature, they sited continuous grain boundary films upon subsequent precipitation of carbides and borides. Grain growth up to ASTM 4 $1 / 2$ impeded ultrasonic inspection and reduced yield strength. Reduced forgeability was reported and attributed to the larger grain size and grain boundary films.

Aubin et al ${ }^{(4)}$ looked closely at the particle surfaces from both argon atomized and rotating electrode atomized Astroloy. In the gas atomized material they found that oxycarbides were predominantly $\mathrm{MC}$ in nature and were generally very stable during heat treatment. The material that was not gas atomized contained less PPB's and more $\mathrm{M}_{6} \mathrm{C}$ carbides that were less prone to form oxy-carbides. During 
the initial stages of HIP consolidation the formation of oxy-carbides can intensify before interdiffusion between powders occur. Aubin et $\mathrm{al}^{(4)}$ also suggested, that during thermal treatment, sulfur would also have the opportunity to segregate to the free surfaces. The roles the sulfur would play and the phases that it would form are unclear. Since sulfur has been known to be a strong agent in reducing hot ductility, its role cannot be overlooked.

Jeandin et al ${ }^{(5)}$ investigated the potential of liquid phase sintering of $\mathrm{P} / \mathrm{M}$ Astroloy followed by HIP and forging. The forging results compared favorably with conventionally HIP processed material. Grain growth in material that has liquid phase present led to increased grain growth compared to conventionally HIPed material.

Grain growth in powder alloys is relatively restrained compared to cast/wrought material. Grain growth in fully annealed cast/wrought UDIMET Alloy 720 occurs as soon as the gamma prime solvus is reached and can readily reach grain sizes of ASTM $0-00^{(6)}$. $\mathrm{P} / \mathrm{M}$ matcrial, on the other hand, experiences minor grain growth after the gamma prime is in solution, limited apparently by the prior particle boundaries $^{(7)(8)}$. This has been suggested since the resultant grain size is approximately equivalent to the average powder mesh size. When P/M materials have been extensively worked grain sizes of up to ASTM 1-2 are possible ${ }^{[8]}$.

Lu et al ${ }^{(9)}$, studying the effect of HIP temperature and powder process method, showed that material with less PPB precipitates (rotating electrode processed (REP) powder) could recrystallize beyond the PPB. Their work, conducted significantly below the alloy solidus, showed no grain growth for argon atomized (AA) powder HIPed above the gamma prine solvus. His observation was that the AA powder had more decorated PPB's compared to REP powder. The carbon and oxygen levels in the AA powder were higher compared to the REP powder.

Extrusion consolidation is also used as a means to break up powder surface structures and to enhance subsequent diffusion ${ }^{(2)}$. Extrusion can produce a consolidated product with uniform fine grains but, subsequent working can only be achieved by isothermal forging due to limited high strain rate ductility and extensive cracking. The cause for this has been attributed to the PPB's.

The purpose of this study was to investigate the benefits of HIP processing a $\mathrm{P} / \mathrm{M}$ superalloy at temperatures just below the solidus to enhance the workability of the HIP consolidation ${ }^{(11)}$. In general it is believed that by growing grain boundaries past PPB's and by rendering the remnant $\mathrm{PPB}$ as dispersed as possible, $\mathrm{P} / \mathrm{M}$ materials will behave more like cast/wrought materials with the added benefit of not having the segregation problems associated with conventional materials.

\section{Experimental Procedure}

Powder for all of the P/M material investigated originated as vacuum induction melted (VIM) filtered master heats to ensure chemistry and then VIM and filtering prior to argon atomization. Powder was processed under argon throughout sieving (-150 mesh) and then vacuum can filled in 304 stainless steel. At the conclusion of the HIP cycles, material was cooled under pressure in the autoclave. Thermocouple readings from the HIP cycles were believed to be reading $16^{\circ} \mathrm{C}$ high and therefore temperatures reported here have been corrected accordingly.
HIP/cogged material was made from $460 \mathrm{~mm}$ dia. compacts that were forged on a 4000 metric ton hydraulic press to 300,230 , and $150 \mathrm{~mm}$ dia. billets. P/M HIP/extruded material was HIP processed at $1121^{\circ} \mathrm{C}$ to $460 \mathrm{~mm}$ dia. and then pushed through a $254 \mathrm{~mm}$ die producing approximately a $3: 1$ reduction ratio.

Cast/wrought material was made from VIM electrodes that were electroslag remelted and then vacuum arc remelted to $508 \mathrm{~mm}$ dia. Ingots were forged on a 4000 metric ton press to $165 \mathrm{~mm}$ dia. billet.

High strain rate tensile ductility testing was performed on standard threaded tensile bars with a $25.4 \mathrm{~mm}$ gauge length and a diameter of $6.4 \mathrm{~mm}$. Test bars were heated to the test temperature, held for $15 \mathrm{~min}$. and then pulled at $50 \mathrm{~mm} / \mathrm{mm} / \mathrm{sec}(2 \mathrm{in} . / \mathrm{in} / \mathrm{sec}$ ).

An ultrasonic inspection technique which included a high sensitivity longitudinal scan and two opposing circumferential shear wave tests was used to inspect the various $\mathrm{P} / \mathrm{M}$ billet forms. The technique was capable of detecting flaws as small as .08 $\mathrm{mm}$ in $\mathrm{P} / \mathrm{M}$ material. Cast/wrought material was inspected utilizing a longitudinal scan to a No.2 $(0.8 \mathrm{~mm})$ flat bottom hole.

Rolldowns were made from samples $(50 \times 50 \times 100 \mathrm{~mm})$ that were rolled longitudinally at $1093^{\circ} \mathrm{C}$ in increments of $2.5 \mathrm{~mm}$ per pass with 5 minute reheats between passes.

\section{$\underline{\text { Results and discussions }}$}

\section{HIP and grain growth}

The effect of grain growth as a function of HIP temperature of P/M UDIMET Alloy 720 is presented in Figure 1. While only a limited number of temperatures were tested, the results suggest grain growth to occur in stages depending on the sequence at which barriers go into solution. As the HIIP temperature increased, the first rapid change in grain size occurred at the gamma prime solvus $\left(-1150^{\circ} \mathrm{C}\right)$. As soon as the gamma prime is in solution, grain sizes increase from ASTM 8 to ASTM 5.5. The microstructure of material HIPed at just above the gamma prime solvus (Figure 2 ) suggest that the very fine powder particles have grown beyond their prior particle boundaries and that the larger powder particles are still restraining grain growth. Many of the large particle areas still have multiple grains within them. Grain growth up until $1254^{\circ} \mathrm{C}$ appears to be restrained by the average particle size in the microstructure $\left(\sim 270\right.$ mesh). Above $1254^{\circ} \mathrm{C}$ and to temperatures below the incipient melting point, rapid grain growth occurs beyond the prior particle boundary of the large particles to grain sizes of ASTM 3-4. Metallographic evidence of the material HIPed just below the solidus temperature (Figure 3 and 4) clearly shows that grain growth has occurred beyond the PPB's which are still clearly decorated in the intragranular microstnucure.

SS-HIP treatments applied to other widely used P/M superalloys appear to respond similarly in terms of grain growth (Figure 5 ). UDIMET Alloy 720, Rene' 88 and Rene' 95 all exhibited similar microstructures. Intercstingly, the same remnants of PPB's can be seen in Rene' 88 and Rene' 95 . The latter two alloys contain niobium (Table I) where UDIMET Alloy 720 does not. One might suspect that if the dissolution of a MC carbide is responsible for grain growth during the SS-HIP treatment then the generally more stable $\mathrm{NbC}$ precipitate would inhibit the reaction. Another suggestion is that 


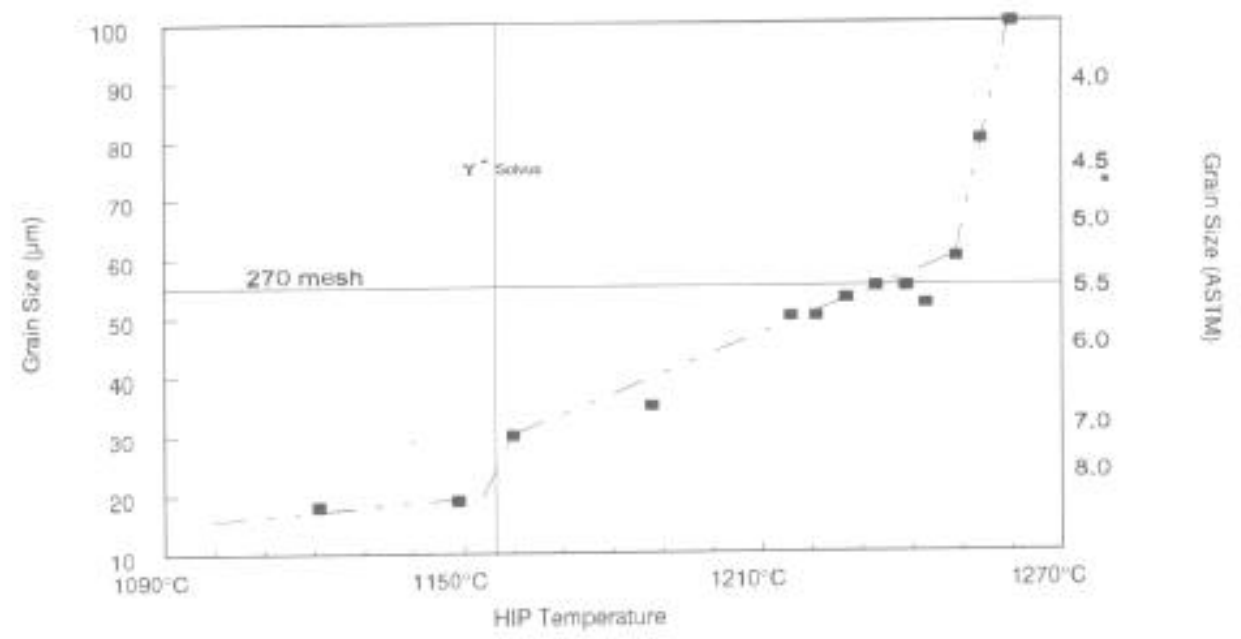

Figure 1: Grain size of hot isostatically pressed P/M UDIMET Alloy 720 at selected temperatures ranging from below the gamma prime solvus to the solidus.
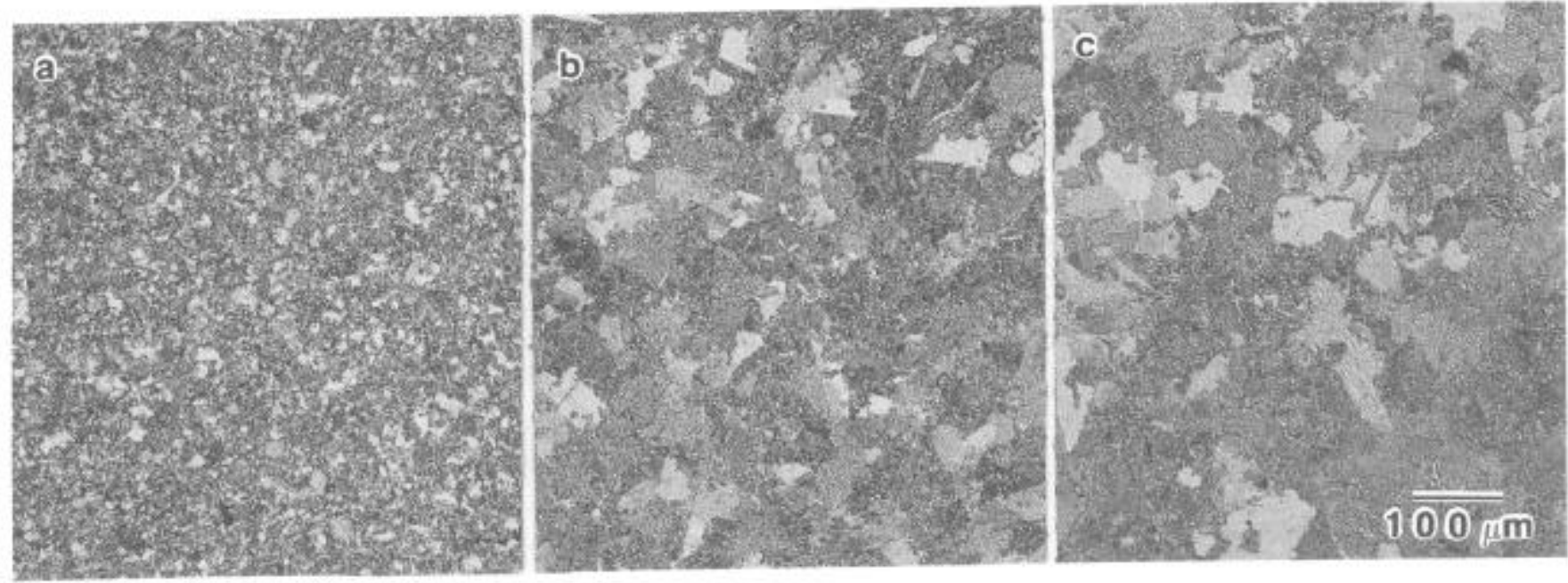

Fivure 2: Typical microstructures of hot isostatically pressed UDIMET Alloy 720. Material is in the as-HIPed condition and etched with Kalling's reagent. a) $1149^{\circ} \mathrm{C}$ b) $1188^{\circ} \mathrm{C}$ c) $1254^{\prime \prime} \mathrm{C}$
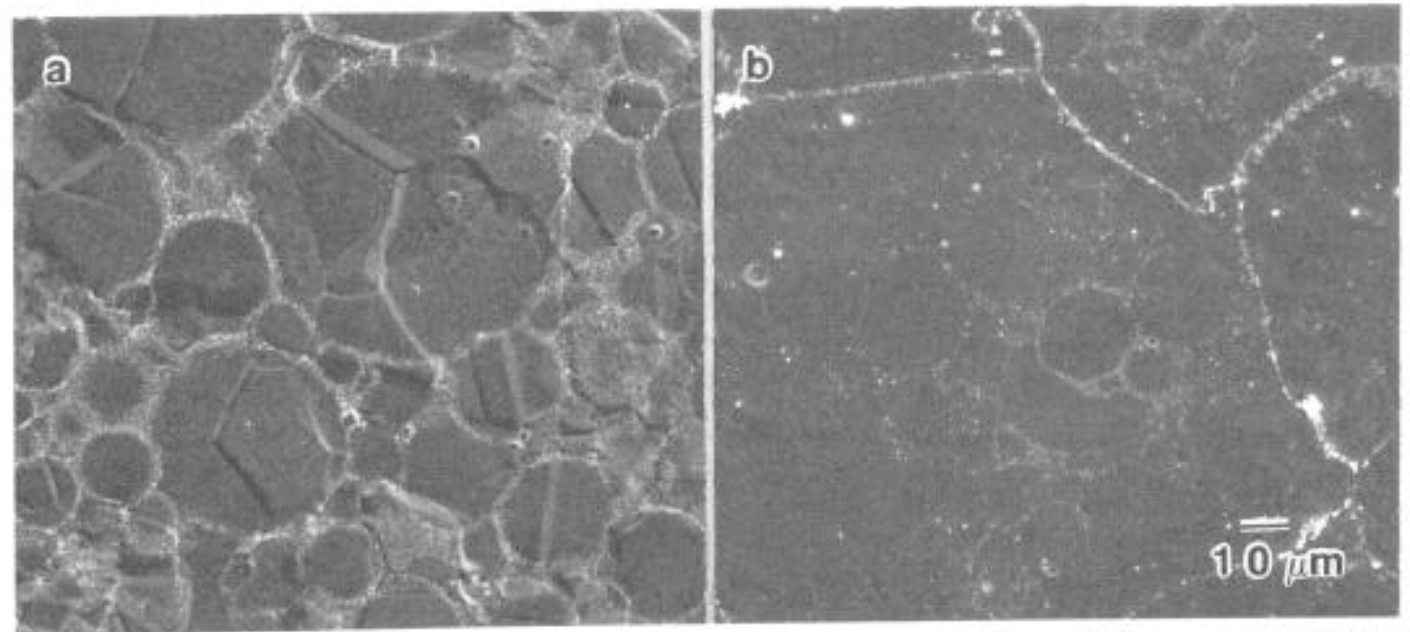

Figure 3: Scanning electron micrographs of UDIMET Alloy 720 that was bot isostatically pressed at a) $1188^{\circ} \mathrm{C}$ b) $1254^{\circ} \mathrm{C}$. Samples were given a $1204^{\circ} \mathrm{C}$ solution to eliminate coarse cooling garmma prime. (Material was electrolytically etched in $5 \% \mathrm{HCL}$ and methanol). 


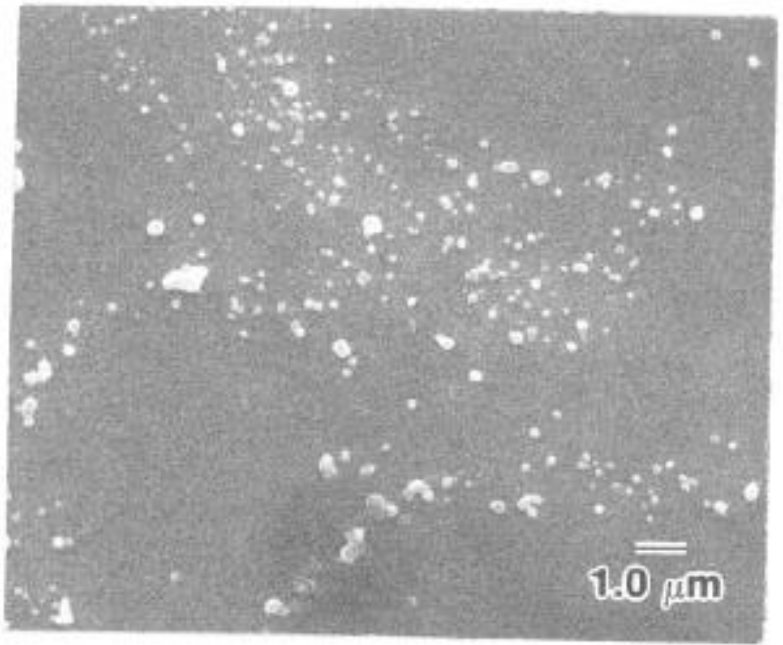

Figure 4: Scanning electron micrographs of UDIMET Alloy 720 that was hot isontatically pressed at $1254^{\circ} \mathrm{C}$ Sample was given a $1204^{\circ} \mathrm{C}$ solution to eliminate coarse cooling gamma prime (Material was electrolytically etched in $5^{\circ}, \mathrm{HCl}$ and methanol.)
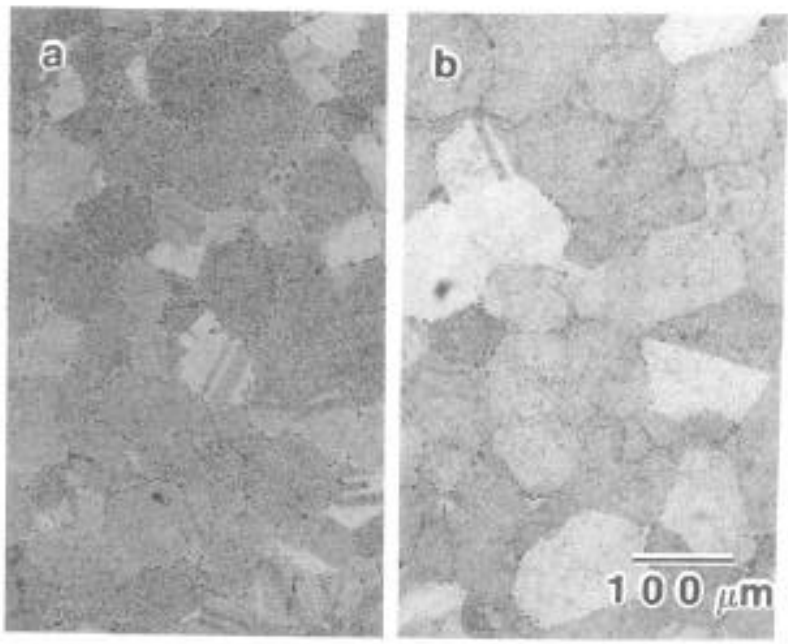

Figure 5: Micrographs comparing the SS-HIP microstructures of various PM superallows a) Rene $88\left(1254^{\circ} \mathrm{C}\right)$ b) Rene $95\left(1260^{\circ} \mathrm{C}\right)$

the nitrides (TiN) and carbo-nitndes in all three alloys would be similar and that all thee alloys would experience similar dissolutions of the phase at the SS-HIP temperatures. Until some detailed analysis of the powder surfaces is documented (the types and amounts of precipitates), it will be difficult to precisely identify the mechanism.
The results suggest that PPB's of the fine particles are not sufficient to be a burrier to grain growth at temperatures just above the gamma prime solvus. However, the coarser PPB's of the larger particles are large enough and densely distributed enough to prohibit grain growth until about $1254^{\circ} \mathrm{C}$ when the desired grain growth oceurs. While it is difficult to document the mechanism for the sudden grain growth, if may be that a portion of the PPB structure is dissolving sufficiently to allow grain growth to proceed. The components of phases that are found in PPB's include carbides. nitrides, borides and oxides ( $\mathrm{Al}, \mathrm{Zr}$ and $\mathrm{Mg}$ ). It seems unlikely that the oxides go into solution but certainly MC carbides and possibly nitrides are candidates. Scanning electron microscopy of the PPB areas (Figure 4) reveal Ti rich phases in the PPB's at $1188^{\circ} \mathrm{C}$ which may have been precipitated during cooling of the samples and probably include carbides and carbo-nitrides. Extraction and $\mathrm{x}$-ray diffraction analysis indicates that the remnant PPB areas of samples HIPed at $1254^{\circ} \mathrm{C}$ are dispersions of fine discrete particle thought to be titanium earbo-nitrides and zircontum oxide. The very fine oxides are not in the form of continuous films as are thought to be present on the as-atomized powder. Further work is needed to determine if the oxides become spheroidized during exposure at the SS-HIP temperature. If continuous films originally existed, then their breakup could be a mechunism that is contributing to the enhanced high strain rate ductilitv

Another possible mechanism for the grain growth observed is that the SS-HIP temperature may be high enough to provide the energy needed to grow the grains beyond the pinning PPB's. Below this critical temperature less grain growth is seen. The growth of the smaller grains at lower temperatures would be explained by Kissinget et al ${ }^{(i)}$ who suggested that smaller powder particles receive more deformation during HIP compared to the larger particles. The higher deformation imparted to these particles could explain why they recrystallize at a lower temperature. However, if the smaller particles were to have fewer oxides associated with them due to moro rapid solidifcation and cooling they would have less resistance to grain growth also

The microstructure in Figure 3 clearly shows how the SSHIP treatment has caused grain growth well bevond a number of PPF regions. The remnant PPB areas contain phases that are extremely fine and relatively dispersed. It is unlikely that these areas are detrimental mechunically and could be areas that are locally dispersion strengthened. Since the high strain rate ductility of the SS-IIIP material improves by at least $50 \%$ once the structure is worked and recrystallized into a fine grain structure the presence of remnant PPB areas does not appear to result in the material reverting back to a situation where the grain boundaries are coincident with detrimental PPB structures.

Table 1 Nominal Composition of Various P/M Superalloys $(w t \%)$

\begin{tabular}{|c|c|c|c|c|c|c|c|c|c|c|c|c|}
\hline Alloy & $\mathrm{Ni}$ & Co & $\mathrm{Cr}$ & $\mathrm{Mo}$ & W & $\mathrm{Nb}$ & $\mathrm{Al}$ & $\mathrm{Ti}$ & $\mathrm{C}$ & $\mathrm{B}$ & $\mathrm{Zr}$ & Other \\
\hline UDIMET Alloy 720 & $\mathrm{Bal}$ & 15.2 & 16.0 & 3.0 & 1.25 & - & 2.5 & 5.0 & .025 & .018 & .03 & - \\
\hline Rene $88^{*}$ & $\mathrm{Bal}$ & 13.0 & 16.0 & 4.0 & 4.0 & 0.7 & 2.2 & 3.75 & .05 & .015 & .05 & - \\
\hline Rene"95 & Bal & 8.0 & 13.0 & 3.5 & 3.5 & 3.5 & 3.5 & 2.5 & .06 & .010 & .05 & - \\
\hline $\mathrm{IN}-100^{* * *}$ & $\mathrm{Bal}$ & 16.0 & 12.5 & 2.8 & - & - & 5.0 & 4.3 & .07 & .02 & .06 & $.9 \mathrm{~V}$ \\
\hline UDIMET Alloy 700 & Bal & 17.0 & 15.0 & 5.0 & . & - & 4.0 & 3.5 & .03 & .02 & .02 & - \\
\hline
\end{tabular}

* Inconel is a revistered rademark of the latemationat Nikel Company 


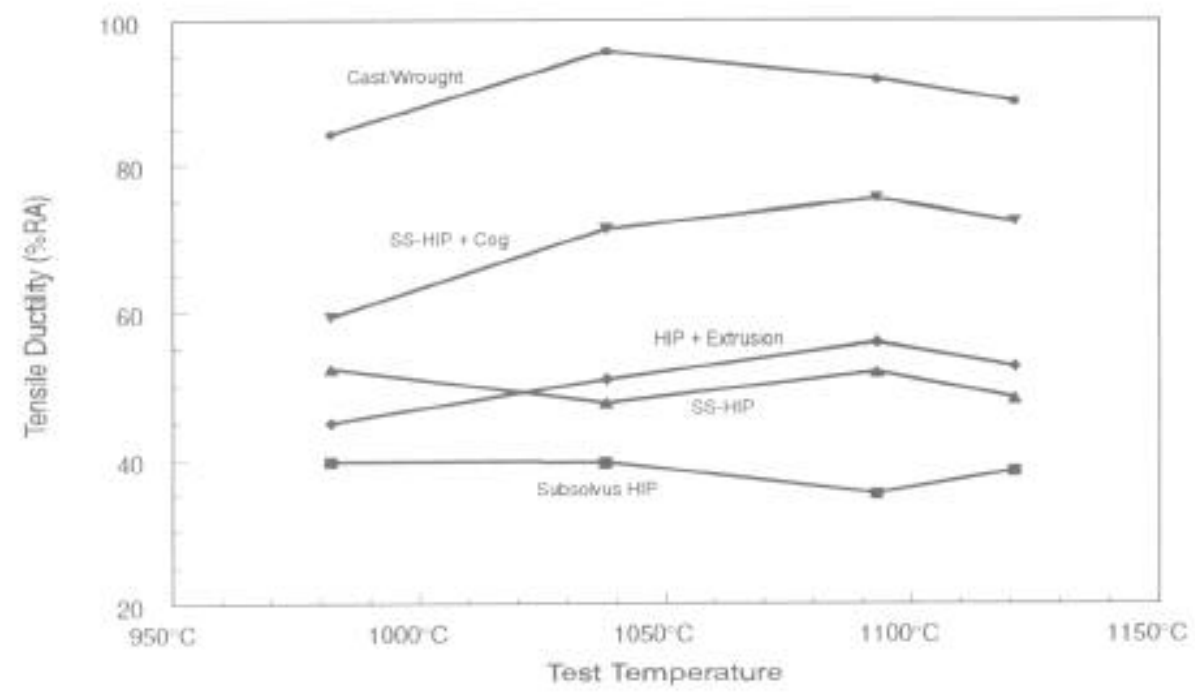

Figure 6: Comparion of high strain rate ductilities of UDIMET Alloy 720 materials tested at common hotworking temperatures. Samples were heated to test temperature, held for $15 \mathrm{~min}$. and then pulled at 50 $\mathrm{mm} / \mathrm{mm} / \mathrm{sec}$, ( 2 in $/ \mathrm{in}$./sec.). Samples were taken circumferentially from transverse slives.

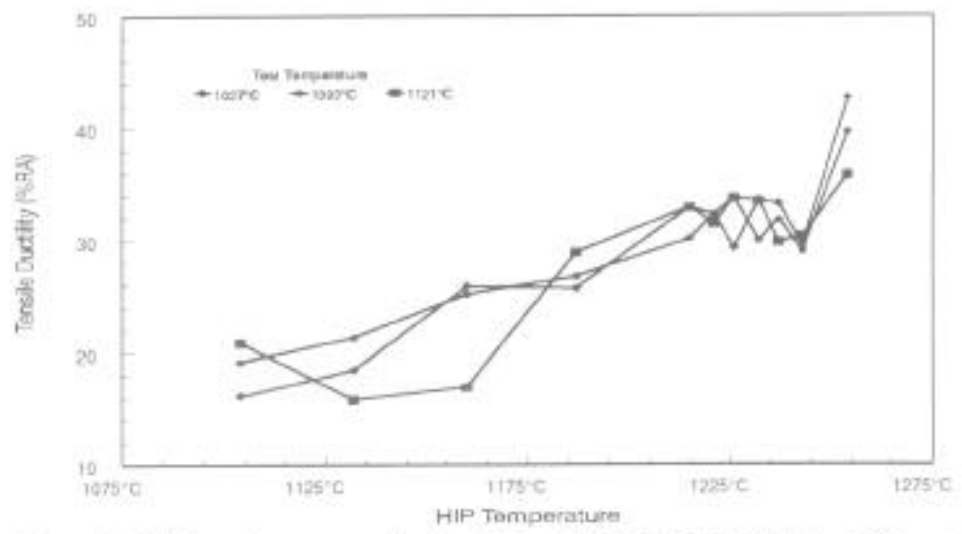

Figure 7: High strain rate tensile ductilities of P/M UDIMET Alky 720 material versus HII temperature. Samples were heated to test temperature, held for $15 \mathrm{~min}$. and then pulled at $50 \mathrm{~mm} / \mathrm{mm} / \mathrm{sec}$, ( $2 \mathrm{in} / \mathrm{in} / \mathrm{sec}$.).

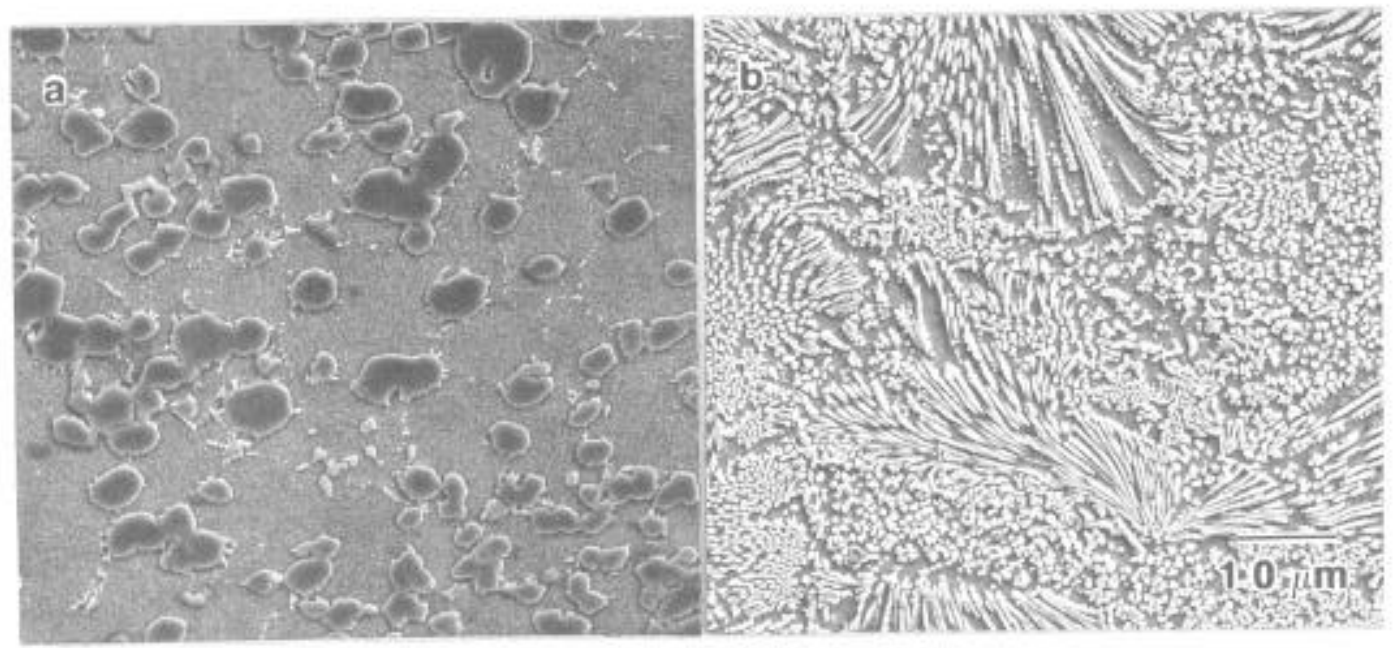

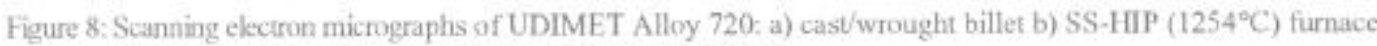
cooled. Material was electrolytically etched in chromate solution. 
Hot workability

The high strain rate tensile results presented in Figure 6 Sow a relative comparison of the hot workability of UDIMET Alloy 720 procesed in a variety of sequences. Test samples were taken from transverse slices and wete generally oriented circumferentially. The corresponding grain size of each condition is presented in Table II. Despite having a very fine grain size of ASTM 9, the material HIPed in the conventional manner had the poorest workability throughout the test range. The material HIPed just below the solidus temperature (Sub-Solidus HIP, SS-HIP) had workability equivalent to P/M-extruded material even though the former had a grain size of ASTM 3-4 and the batter had a grain size of ASTM 9.5. Furthermore, when the SS-HIP material was either cogged or rolled until it had a grain size of ASTM 8-10 the ductility increased to approach that of conventional cast/wrought material.

Table II Grain Size of UDIMET Alloy 720

\begin{tabular}{ll}
\hline \multicolumn{1}{c}{ Process } & ASTM No. \\
\hline Sub-Solvus HIP & $8-9$ \\
Sub-Solidus HIP & $3-4$ \\
Sub-Solidus HIP + Cog & $8-9$ \\
HIP + Extrude & $9-10$ \\
Cast/Wrought & $9-10$ \\
\hline
\end{tabular}

Samples were not tested from longitudinal sections. however, it is expected that different results would be observed. The HII/extruded material, for example, would be expected to have greater ductility along the longitudinal direction. Measuring hot workability in transverse sections is believed to be a better measure of the critical workability that is needed during forge shop operations since most operations begin with upset deformation.

The effect of HIP temperature on high strain rate ductility is further defined in Figure 7 where the reduction in area at $1066^{\circ} \mathrm{C}$ is compared for the same lot of P/M UDIMET Alloy 720. Improvement of ductility is reported for HIP temperatures from $1149^{\circ} \mathrm{C}$ to $1190^{\circ} \mathrm{C}$. From $1190^{\circ} \mathrm{C}$ to $1254^{\circ} \mathrm{C}$ the tensile ductility appears to level out before an increase in ductility is experienced when the SS-HIP condition is reached. The ranges in which ductility is improved are somewhat similar to the grain growth behavior shown in Figure 1. It would be difficult to clearly sort out the mechanisms that improves ductility over the $1149^{\circ} \mathrm{C}$ to $1190^{\circ} \mathrm{C}$ range. Grain growth beyond the weak PPB's of the smaller powder particle could account for the improvement. However carbides and borides going into solution could also be beneficial.

The high strain rate ductility enhancement that is reached when the SS-HIP condition is met, clearly suggests that PPB's are deleterious to hot ductility. Despite the coarse grain condition, the ductility of SS-HIP material is superior to fine grain material where the grain boundaries are coincident with the PPB boundaries of the coarser powder. In the extruded $\mathrm{P} / \mathrm{M}$ material the high strain rate ductility (Figure 6) was being limited by the PPB's because large portions of them are still coincident with the recrystallized grain boundaries. The ductility of the extruded material is superior to the ductility of the conventional HIPed material apparently due the presence of some new grain boundary areas and PPB areas that are somewhat more dispersed than the as-HIPed conventional material.
The superior high strain rate ductility of the cast/wrought material was consistent throughout this study. An examination of the microstructure (Figure 8) suggests that the very coarse gamma prime precipitate softens the gamma matrix and therefore accommodates plastic strain better. The grain boundaries of the cast/wrought material also appear more discrete and tend to be less continuous.

Throughout this investigation the role of isostatic pressing during the IIIP process was questioned. Obviously the isostatic forces are necessary to bond the powder particles together but whether stress is necessary to aceelerate the dissolution of phases and to allow the SS-HIP grain growth to occur is still not completely defined or understend. Samples of material HIPed at $1243^{\circ} \mathrm{C}$ were heat treated in air at the SS-HIP Iemperature condition $(12605 \mathrm{C})$ and were tested mechanically and examined micrestructurally. The heal treat cycle was successfial in producine grain growth. However. Figure ? clearly shows that not only was the ductility not impreved. the matcrial lost nearly half of its ductility. The cause for degradation in properties was immediately suspected to he a result of thermally induced porosity (TIP) Mecrestructural examination confirmed that porosity did occur and was most likely responsible for the loss in high strain rate ductility (Figure 10). TIP features in gas atomized powder is a common phenomena and is a result of trapped argon gas within particles. HIP is capable of essentially closing argen filled voids, but if the material is subiected to high temperatures, well above the gamma prime solvus. the intense internal gas pressure is capable of reopening the voids. Conventional heat treatments of P/M superalloys are at low enough temperatures that the reoceurrence of TIP is not a problem.

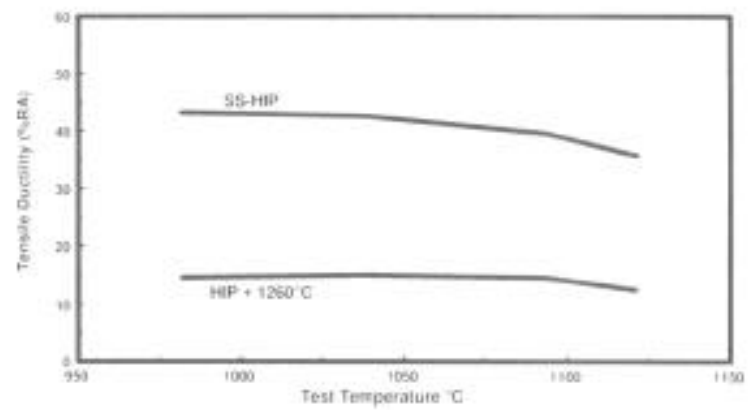

Figure 9: Comparison of the high strain rate tensile ductilitics of PIM UDIMET Alloy 720 material that was SS-HIPed and material that was HIPed at $1243^{\circ} \mathrm{C}$ and heat treated at $1260^{\circ} \mathrm{C}$

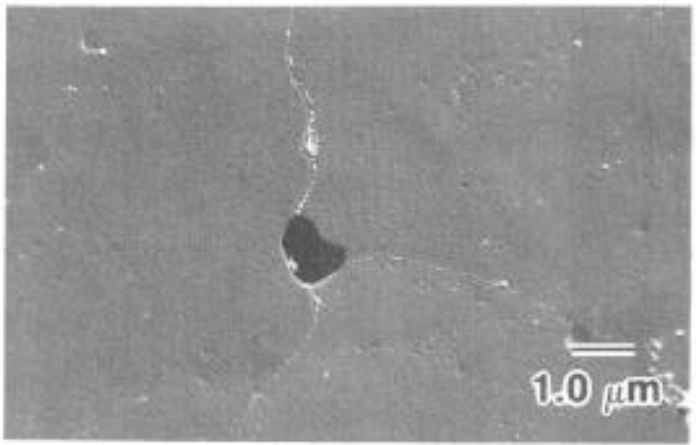

Figure 10: Scanning electron micrographs of P/M UDIMET Alloy 720 that was hot isostatically pressed at $1188^{\circ} \mathrm{C}$ and then heat treated at $1260^{\circ} \mathrm{C}$. Void that is believed to be associated with TIP is shown. (Material was electrolytically etched in $5 \% \mathrm{HCl}$ and methanol.) 
While it appears that HIP is needed to achieve void free material at temperatures in the SS-HIP range, it is believed that the isostatic condition may be extending the useful process temperature range by increasing the incipient melting temperature. If there is any incipient melting during the HIP cycle, any melt-related void, that would normally occur during heat treatment at ambient temperature, would be readily closed. The effect of incipient melting on subsequent hot workability and mechanical properties has not been fully investigated.

The effect of cooling rates from the HIP temperature would be expected to influence both the gamma prime structures and also the size and morphology of the carbides and borides on the grain bxundaries. This study did not try to sort out this effect but we would expect contributions to the high strain rate ductilities.

\section{Thermal mechanical processing}

The benefits of SS-HIP are most apparent after the as-HIPed coarse grain material is worked sufficiently to refine the grain size as is seen in HIP/cogged material (Figure 6). A series of rolldowns was prepared with different amounts of reductions to determine what amount of work is needed to maximize hot workability in SS-HIP material (Figure 11). It was found that with as little as $20 \%$ reduction the bigh strain rate ductility increased from $45 \%$ to nearly $90 \%$ at $1037^{\circ} \mathrm{C}$. Microstructural examination of the rolldown did not reveal any readily apparent fine grain recrystalization. However, it would be expected that a fine grain substructure had developed but was not yet defined enough to be made apparent by etching.

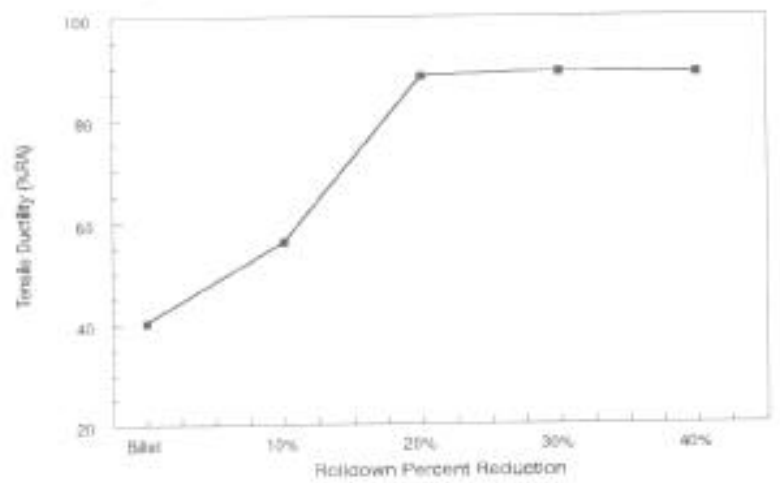

Figure 11: High strain rate tensile ductility of P/M UDIMET Alloy 720 SS-HIP material versus folldown reductions.

This result is useful for developing conventional forging practices for SS-HIP material for producing cogged billets or to produce forge parts directly from SS-HIP material. The result demonstrates that if a forger were to initially get suflicient work into the SS-HIP structure, subsequent workability improves dramatically. Production trials have shown that SS-HIP material has hot workability that is superior to cast/wrought ingots. While the high strain rate tensile results in this paper may suggest that the ductility of cast/wrought billets is excellent, the presence of surface defects and imperfections on a cast ingot causes nuisances during forging operations. The SS-HIP material on the other hand is extremely uniform in bulk and comes with a well bonded stainless steel can that provides thermal insulation and lubrication during initial breakdown operations.

The versatility of SS-HIP material is fully demonstrated by the trial production of conventionally ring-rolled parts that were manufactured directly from SS-HIP material rather than from SS-HIP cogged billet. Ring rolling is a severe test since the strain rates are high and sensitivity to surface cooling is most pronounced. Ring rolling of the fine grain SS-HIP material was compared with the excellent results that are experienced with lower strength alloys like Waspaloy.

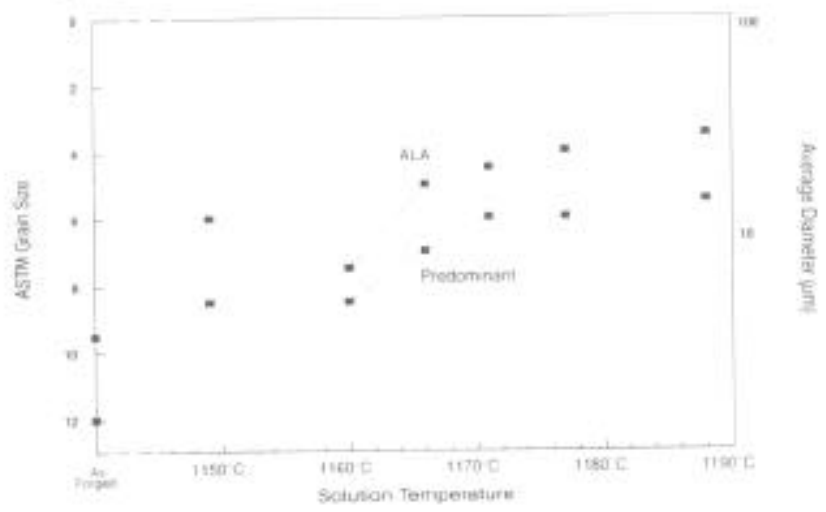

Figure 12: Grain size of ring rolled P/M SS-HIP UDIMET Alloy 720 as a function of solution heat treatment temperature. (Provided by Schlosser Forge Co.)

Ring-rolled parts have been evaluated to determine the grain growth response when supersolvus heat treated (Figure 12). The results define a wide range in temperatures that can be used to achieve controlled grain growth when desired. The grain size that can be achieved is larger than what can be achieved with conventional P/M material where uniform grain sizes greater than ASTM 6-8 are more difficult to achieve. The grain growth of SS-HIP material is much more uniform than cast/wrought material which is subject to banding due to solidification segregation. As with all superalloys, conditions were identified where certain strain conditions led to abnormal grain growth above the gamma prime solvus.

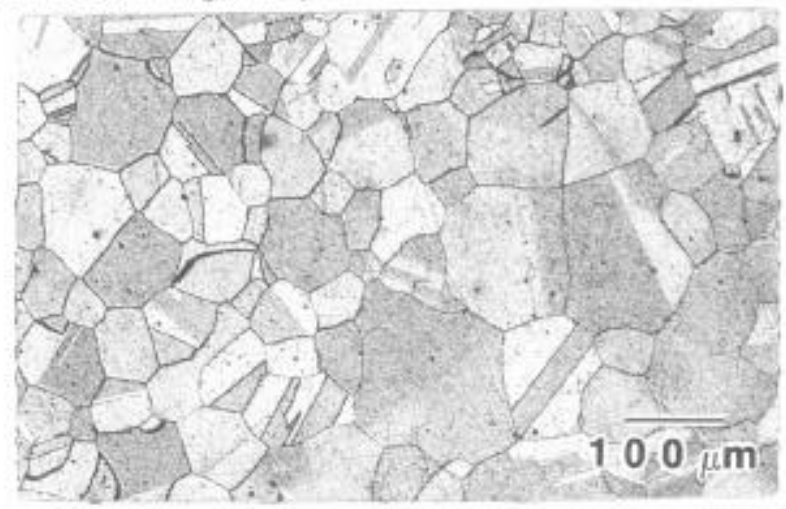

Figure 13: Micrograph of ring-rolled P/M SS-HIP UDIMET Alloy 720 that was solution beat treated to provide a uniform ASTM 4.5 grain size. (Kallings etch)

Figure 13 illustrates a uniform grain size of a conventional ring rolled part. The uniform grain size of ASTM 4.5 provides a microstructure that potentially has balanced creep, tensile, and fatigue properties. It is speculated that, by minimizing the effects of PPB's. enhancement in mechanical properties over conventionally processed $\mathrm{P} / \mathrm{M}$ superalloys will be realized. Also, forgings made directly from SS-HIP billet offers a cost-effective approach to make superior parts with short lead times and improved process control. 
$\underline{\text { Inspectability }}$

A comparison of UDIMET Alloy 720 billet ultrasonic inspectability ( Table III) highlights the advantages of $\mathrm{P} / \mathrm{M}$ processing in reducing inspection noise levels and improving the detection of smaller defects. While one would expect better inspectability for finer grain sizes, cast/wrought appears to an exception to the rule. Despite having a grain size as small as P/M processed materials, ASTM 11, the detection limit of cast/wrought material has coarse macrostructural features, such as low angle grain macro grain boundaries, that are believed to cause gross noise levels.

Table III Inspectability of UDIMET Alloy 720

\begin{tabular}{lccr}
\hline Form & $\begin{array}{c}\text { Billet Dia. } \\
(\mathrm{mm})\end{array}$ & ASTM G.S. & $\begin{array}{c}\text { Noise Level } \\
\text { FBH* }\end{array}$ \\
\hline P/M Extruded & $150-300$ & 14 & $6 \% @ \# 1$ \\
P/M SS-HIP/Cog & 300 & 10 & $25 \% @ \# 1$ \\
P/M HIP & 165 & 10 & $15 \% @ \# 1$ \\
P/M SS-HIP & 300 & 3 & $50 \% @ \# 1$ \\
Cast/Wrought & 165 & 11 & $100 \% @ \# 2$ \\
\hline
\end{tabular}

* \# $1=1 / 64=0.40 \mathrm{~mm}$

\section{Conclusions}

1) Grain growth restriction of $P / M$ superalloys by $P P B$ can be overcome by HIP at temperatures just below the alloy's solidus.

2) By eliminating grain boundaries that are coincident with PPB's, the high strain rate ductility of a $\mathrm{P} / \mathrm{M}$ superalloy can be improved.

3) SS-HIP P/M UDIMET Alloy 720 exhibits sufficient high strain rate ductility that conventional forging and ring rolling of billet is practical.

4) Post forging super-solvus heat treatments exhibit uniform grain growth and resistance to abnormal grain growth.

5) SS-HIP material has superior ultrasonic inspectabily compared to cast/wrought material.

\section{Acknowledgments}

The authors wish to thank Prof. John Radavich for his insightful analysis of the microstructures and his helpful discussions regarding potential mechanisms. We would also like to thank Steven Sawochka and Schlosser Forge Company for providing us data and samples from ring rolling trials and Howmet Corporation in Whitehall, Michigan for providing HIP services.

\section{$\underline{\text { References }}$}

1. R. Thamburaj, A.K.Kroul, W. Wallace, and M.C.deMalherbe, "Prior Particle Boundary Precipitation in $\mathrm{P} / \mathrm{M}$ Superallnys," Mndern Developments in Powder Metallurgy, Proceeding of the 1984 International Powder Metallurgy Conference, (Princeton, NI: Metal Powder Industries and the American Powder Metallurgy Institute, 1984), 635-674.

2. R.Chang, D.D.Krueger, and R. A. Sprague, "Superalloy Powder Processing, Properties and Turbine Disk Applications," Superalloys 1984, Proceedings of the Fifth International Symposium on Superalloys, (Warrendale, PA: TMS-AIME, 1984), 245-273.
3. G.A.J.Hack, J.W.Eggar, and C.H.Symonds, "A Comparison of APK-1 Consolidated at HIP Temperatures Above and Below the Boride Solvus," Proceedings, Powder Metallurgy Superalloys Conference, Zurich, November 1980, 20.1-20.50.

4. C. Aubin, J.H. Davidson, and J.P.Trottier, "The Influence of Powder Particle Surface Composition on the Properties of a Nickelbased Superalloy Produced by Hot Isostatic Pressing," Superalloys 1980, Proceedings of the Fifth International Symposium on Superalloys, (Metals Park, OH: ASM International, 1980), 345-354.

5. M. Jeandin, B. Fieux and J.P.Trottier, "P/M Astroloy Obtained by Forging or Hiping Supersolidus Sintered Preforms," Modern Developments in $\mathrm{P} / \mathrm{M}$, Vol. 14, Special Materials, MPIF/APMI, 1981, 65-91.

6. K.R.Bain, M.L.Gamone, J.M.Hyzak, and M.C.Thomas, "Development of Damage Tolerant Microstructures in Udimet 720," Superalloys 1988, Proceeding of the International Symposium on Superalloys, (Warrendale, PA: TMS, 1988), 13-22.

7. C.H.Symonds, J.W. Eggar, G.J. Lewis, and R.J.Siddall, "The Properties and Structures of As-HIP Plus Forged Nimonic APK 1 (Low Carbon Astroloy)", Proceeding Powder Mctallurgy Superalloys Conference, Zurich, 1980, 17.1-17.28.

8. J.M. Hyzak, R.P.Singh, J.E.Morra, and T.E.Howson, The Microstructural Response of As-HIP P/M U-720", Superalloy 1992, Proceeding of the International Symposium on Superalloys, (Warrendale, PA: TMS, 1992), 93-101.

9. T.C. Lu, T.T.Nguyen, Y, Bienvenu, J.H.Davidson, and O.Dugue, "The Influence of Powder Processing Variables on the Structure and Properties of HIPed Low Carbon Asroloy" (Publication unknown)

10. R.D.Kissinger, S.V.Nair, and J.K.Tien, "Influence of Powder Particle Size Distribution and Pressure on the Kinetics of Hot Isostatic Pressing (HIP) Consolidation of P/M Superalloy Rene 95," Superalloys 1984, Proceedings of the Fifth International Symposium on Superalloys, ( Warrendale, PA: TMS-AIME, 1984), 285-294.

11. US Patent No. 5,451,244, "High Strain Rate Deformation of Nickel-Base Superalloy Compact", B. Wayne Castledine, Special Metals Corporation. 